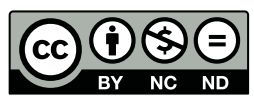

Estudos Teológicos foi licenciado com uma Licença Creative Commons Atribuição - NãoComercial - SemDerivados 3.0 Não Adaptada

http://dx.doi.org/10.22351/et.v.57i2.2972

\title{
ReFormas ANTES DA ReFORMA: INVESTIGANDO ANTECEDENTES DA REFORMa LuTERANA do SÉCUlo XVI ${ }^{1}$
}

\author{
Reformations before the Reformation: \\ investigating antecedents of the Lutheran Reformation from the 16th century
}

\section{Carlos Ribeiro Caldas Filho ${ }^{2}$}

Resumo: No ano em que se celebra em todo o planeta o quinto centenário da Reforma Protestante do século XVI é importante fazer um resgate das propostas de busca de revitalização espiritual e reforma de estruturas eclesiásticas que houve antes de Lutero. Alguns desses movimentos foram reprimidos com violência. Outros, ou foram assimilados pelo poder eclesiástico de seu tempo ou sobreviveram de alguma maneira. Trabalhando a partir do conceito de história de longa duração de Fernand Braudel, o presente artigo visa destacar alguns desses movimentos. Pretende-se assim estudar a Reforma não a partir de uma perspectiva romântica e ingênua, mas a partir de uma perspectiva "pé no chão", que reconhece que o movimento iniciado por Lutero foi antecedido por vários outros, alguns, séculos antes. Tal abordagem, por conseguinte, tem o potencial de ser útil para estudar a Reforma Protestante não da perspectiva do confronto e da apologética denominacional, mas de uma perspectiva ecumênica, com ênfase nos pontos de convergência entre a Reforma propriamente e seus antecedentes medievais.

Palavras-chave: Lutero. Reforma. Movimentos medievais de busca espiritual. Devotio moderna.

Abstract: In the year that the fifth centennial of the Protestant Reformation of the 16th century is celebrated all over the world, it is important to rescue the proposals of seeking spiritual revitalization and reform of the ecclesiastical structures that have happened before Luther. Some of these movements were violently repressed. Others, were assimilated by the ecclesiastical power of the day, or survived somehow. Working with Fernand Braudel's concept of history of long duration, this article intends to highlight some of these movements. Therefore, there is the aim of studying the Reformation not from a romantic or naïve perspective, rather, from an ecumenical perspective, with emphasis in the elements of convergence between the Reformation itself and its medieval antecedents.

Keywords: Luther. Reformation. Medieval movements of spiritual seeking. Devotio moderna.

1 O artigo foi recebido em 18 de março de 2017 e aprovado em 05 de junho de 2017 com base nas avaliações dos pareceristas ad hoc.

2 Doutor em Ciências da Religião pela Universidade Metodista de São Paulo (2000), com estágios de pós-doutoramento concluídos na FAJE - Faculdade Jesuíta de Filosofia e Teologia em Belo Horizonte (MG), com apoio do PNPD-CAPES. Contato: orcid.orgcrcaldas2009@hotmail.com 


\section{Introdução}

O grande tema acadêmico do ano 2017 é a lembrança do quinto centenário da Reforma Protestante. Esse movimento, liderado por Martim (ou Martinho) Lutero, foi uma expressão da ânsia por revitalização da vivência da fé e a busca de um retorno $a d$ fontes, isto é, o esforço para recuperar a força e a pureza originais da fé cristã. Na verdade, tal desejo sempre esteve presente na história do cristianismo. A Reforma Protestante do século XVI se enquadra nessa busca, mas não foi de modo algum o único movimento a ter essas preocupações. O movimento iniciado por Lutero foi bem-sucedido por diferentes motivos de natureza política (que não serão aqui elencados, para não se incorrer em desvio do tema), mas foi antecedido por vários outros. Dentre as características mais marcantes desses movimentos podem ser citadas a busca de uma espiritualidade intensa, um aprofundamento da vida de relacionamento com Deus por meio da fé em Cristo e uma valorização da leitura bíblica. Daí o pressuposto básico do presente artigo: a Reforma do século XVI é herdeira de vários movimentos que buscaram reformar o cristianismo. Logo, a Reforma não foi criada "do nada", pois ex nihilo nihil fit. Em outras palavras: Lutero não "inventou a roda", pois foi antecedido por vários outros movimentos que anteciparam muitas de suas bandeiras e conclusões teológicas.

Do século XI ao XV encontram-se vários esforços de revitalização e reforma do cristianismo. Alguns desses movimentos foram considerados heréticos pela igreja e, consequentemente, foram perseguidos. Outros seguiram seu caminho em paz com as lideranças eclesiásticas. Este artigo então, além do seu pressuposto operacional básico já apresentado, sugerirá uma tipologia dupla em sua abordagem aos movimentos de reforma antes da Reforma: (1) movimentos que foram perseguidos e suprimidos violentamente (sendo que desses, alguns desapareceram por completo, e outros, lograram êxito em sobreviver) e (2) movimentos que foram assimilados e incorporados pela igreja de seus dias.

\section{A "história de longa duração" como base teórica para uma aproximação aos movimentos de reformas antes da Reforma}

Como referencial teórico para esta abordagem será utilizada uma intuição proveniente da École des Annales francesa. Nessa proposta teórica de historiografia, um autor que particularmente se destaca como útil para os propósitos do presente artigo é Fernand Braudel (1902-1985)³. O grande mérito de Braudel está em ter mudado a concepção teórica de tempo ao desenvolver uma noção de tempo que se constitui em

\footnotetext{
Fernand Braudel e Claude Lévi-Strauss foram convidados por Julio de Mesquita Filho para auxiliar no processo da criação da primeira universidade do Brasil, a Universidade de São Paulo (USP), no início da década de 1930. O brasilianista estadunidense Thomas Skidmore recolheu um testemunho do próprio Braudel, no qual o historiador francês afirmou que seu tempo no Brasil foi "o melhor período da sua vida”. Cf. SKIDMORE, Thomas. Levi-Strauss, Braudel and Brazil: A Case of Mutual Influence. Bulletin of Latin American Research, v. 22, n. 3, p. 340-349, 2003.
} 
alternativa à visão positivista, de inspiração rankeana ${ }^{4}$, que estuda os acontecimentos históricos como passados, prontos e acabados. Essa história tradicional é a que Braudel chama de "história de curta duração":

Todo trabalho histórico decompõe o tempo decorrido, escolhe entre suas realidades cronológicas, segundo preferências e opções exclusivas mais ou menos conscientes. A história tradicional, atenta ao tempo breve, ao indivíduo, ao evento, habituou-nos há muito tempo à sua narrativa precipitada, dramática, de fôlego curto ${ }^{5}$.

De igual maneira, Braudel também propõe uma alternativa à visão marxista de história, que propõe uma "aceleração" do tempo, por assim dizer, pela via da revolução, e que concentra sua atenção apenas no econômico. Para Braudel - e de resto, para toda a École des Annales -, o ser humano é um ser integrado, e não deve ser estudado apenas como homo sapiens, homo ludens, homo faber, homo economicus ou homo religiosus. Tais reducionismos não têm lugar na teoria de história proposta pela École des Annales. Isso por partir do pressuposto que o humano é o humano, que não pode ser estudado em blocos ou compartimentos estanques, como se um tivesse mais importância que qualquer outro.

A proposta de pesquisa e estudo da história da École des Annales em geral, e de Braudel em particular, resgata a visão agostiniana de tempo ${ }^{6}$, vendo-o como um presente contínuo. Conforme Braudel, há o tempo de curta duração (o evento em si), o tempo de longa duração (o tempo das estruturas, que dão base ao evento) e o tempo de longuíssima duração (o tempo da natureza), diante do qual o ser humano é completamente passivo. Vale lembrar que, para Braudel, os três tempos agem simultaneamente sobre o ser humano e sobre os eventos históricos propriamente. ${ }^{7}$

Tomando então como pressuposto teórico a proposta de tempo de longa duração de Braudel, será possível estudar os movimentos de busca espiritual da Alta Idade Média, como movimentos de reforma antes da Reforma. Pois, conforme Braudel, para se entender um determinado acontecimento (no caso, a Reforma Protestante do século XVI) é necessário olhar não apenas para o tempo do evento em si, mas para as circunstâncias anteriores ao mesmo, que, não raro, podem ter tido lugar na história séculos antes.

4 Referente a Leopold von Ranke (1795-1886), tido como o “pai da história moderna”. Sua proposta de historiografia "científica", bem de acordo com o Zeitgeist racionalista do século XIX, era produzir uma história com foco nas grandes questões políticas (Außenpolitik), com a intenção de relatar os fatos wie es eigentlich gewesen ist ("como eles realmente aconteceram").

5 BRAUDEL, Fernand. Escritos sobre a história. São Paulo: Perspectiva, 1978. p. 44.

6 A respeito da visão agostiniana da história, o historiador Maurice Gandillac anotou: "Em geral, considera-se Agostinho como um dos pais da 'filosofia da história'; certamente, seria melhor vê-la como uma 'teologia do tempo', pois a sequência dos acontecimentos, tal como ele a encara, diz respeito menos ao desenvolvimento das sociedades enquanto tais que à sua posição (aliás pouco discernível) no interior de um processo, ao mesmo tempo, cósmico e escatológico". GANDILLAC, Maurice. Gêneses da modernidade. Rio de Janeiro: Editora 34, 1995. p. 13.

7 BRAUDEL, 1978, p. 41-59. 
É oportuno apresentar exemplos de usos da noção de tempo de longa duração de Braudel. Um é o feito pelo acadêmico brasileiro Henrique Claudio de Lima Vaz, em seu estudo sobre a modernidade. Vaz rejeita a ideia apresentada por muitos historiadores positivistas que a indicam como tendo tido início no século XVIII com o Iluminismo. Para Vaz, a modernidade ocidental teve início bem antes, no século XIII: "Ao buscarmos as raízes da modernidade, a investigação acaba por levar-nos ao coração da Idade Média, a esse século XIII, no qual a civilização medieval atingiu seu apogeu e iniciou seu declínio"».

O já mencionado filósofo francês Maurice de Gandillac, por sua vez, compreende que a raiz remota da modernidade ocidental é ainda anterior, pois seria encontrada em Agostinho, que viveu no período de transição entre a idade antiga e a medieval. Para Gandillac, em De Civitate Dei, ao falar sobre a cidade do homem distinta da cidade de Deus, Agostinho estaria pavimentando o caminho para a secularização que o Ocidente começa a testemunhar com o Iluminismo, no século XVIII. ${ }^{9}$

Tendo apresentado a base teórica para o presente artigo e seus pressupostos fundamentais, pode-se prosseguir.

\section{Movimentos de reforma espiritual na Idade Média}

Nessa perspectiva, não é demais repetir que em toda a Idade Média houve muito interesse no desenvolvimento da espiritualidade. De acordo com Alister McGrath, “[...] há um consenso hoje em dia de que os séculos 14 e 15 não testemunharam uma diminuição geral no interesse pela religião cristã na Europa ocidental"10. Com essa opinião concorda o historiador Lucien Febvre, que afirmou que a Baixa Idade Média (período que, grosso modo, vai dos séculos XIII ao XV) foi marcada por "imenso apetite pelo divino"11. Outro medievalista que chega à mesma conclusão quanto ao interesse - e diversidade - pela religião no período do fim da Idade Média, que antecede imediatamente o objeto de estudo principal da presente pesquisa, é o holandês Johan Huizinga, em sua obra $O$ declínio da Idade Média, que se tornou um clássico nos estudos do tema:

O aspecto geral que apresenta a vida religiosa em França no fim da Idade Média é o de uma prática muito caída na rotina e no relaxamento, entremeada de efusões espasmódicas de piedade ardorosa. A França era estranha a essa forma especial de pietismo que se sequestra em pequenos círculos de devotos ferventes, tal como os encontramos nos Países Baixos: a devotio moderna dominada pela figura do Tomás Kempis. E, todavia, os anseios religiosos que deram lugar a este movimento não faltavam em França; os devotos é que não formaram uma organização especial. Encontraram um refúgio nas

8 VAZ, Henrique C. de Lima. Raízes da modernidade. 2. ed. São Paulo: Loyola, 2012. p. 31. (Escritos de filosofia VII).

9 GANDILLAC, 1995, p. 11-22.

${ }^{10}$ McGRATH, Alister. Origens intelectuais da Reforma. São Paulo: Cultura Cristã, 2007. p. 21.

${ }^{11}$ Citado por GEORGE, Timothy. Teologia dos Reformadores. São Paulo: Vida Nova, 1994. p. 33. 
ordens existentes ou permaneceram na vida secular sem se distinguirem da massa dos crentes. É provável que a alma latina suporte mais facilmente do que a dos povos do Norte os conflitos a que a vida mundana sujeita os homens de grande ardor religioso ${ }^{12}$.

Portanto houve em toda a Idade Média vários movimentos de busca espiritual, esforços de revitalização da vivência da fé. Alguns foram considerados heréticos e perseguidos de maneira severa. Outros se mantiveram fieis à igreja e conseguiram exercer influência que se faz notar até os nossos dias. Um desses é o movimento dos albigenses (assim chamados por estarem ligados à cidade de Albi, na região do Languedoc, sudoeste da França), do século XIII. Foram considerados heréticos por conta de muitas ênfases estranhas à ortodoxia cristã, como a crença em um dualismo de estilo maniqueísta, o que os levava a negar a Trindade (crendo em dois poderes, um do bem e um do mal, negavam a fé trinitária). Mas eles tinham ao mesmo tempo ênfases saudáveis, como a busca por santidade na vida, a condenação da violência, a rejeição das riquezas e o desprezo das estruturas de poder eclesiástico. ${ }^{13}$ Os albigenses foram severamente perseguidos, a ponto de serem alvo de uma cruzada ordenada pelo papa Afonso III.

Associados de certa forma aos albigenses eram os cátaros (os dois movimentos algumas vezes se confundem). A palavra cátaro é de origem grega e significa "puro". O nome do grupo remete à sua busca por santidade na vida. Mas os cátaros, assim como os albigenses, tinham crenças que foram rejeitadas pela igreja de seu tempo, como a já mencionada ênfase dualista e a crença de serem eles a única igreja verdadeira. É bem verdade que não se sabe muito a respeito do que os albigenses e cátaros realmente criam, pois o que se conhece sobre eles foi dito por seus adversários. É o caso dos bogomilos, de origem búlgara, do século XI. ${ }^{14}$ Esses movimentos, por conta da repressão violenta, sofreram solução de continuidade, não deixando influências posteriores. ${ }^{15}$

Também há que se mencionar movimentos populares de busca espiritual como o das beguinas e begardos e o movimento dos flagelantes. O movimento das beguinas foi forte nos Países Baixos (especialmente na atual Bélgica) e era formado por mulheres que se uniam em grupos para uma vida de pobreza, oração e devoção. Conforme Justo Gonzalez:

É muito provável que em parte este impulso entre as mulheres foi motivado pelo fato de a vida monástica ser o único meio em que elas, mesmo as mais ricas, podiam escapar

12 HUIZINGA, Johan. O declínio da Idade Média. 2. ed. Lisboa: Ulisseia, 1996. p. 133.

${ }^{13}$ Cf. CLOUSE, Robert G. Albigenses. In: Enciclopédia Histórico-Teológica da Igreja Cristã. São Paulo: Vida Nova, 1988. v. I, p. 36-37.

14 AKERS, John. Bogomilos. In: Enciclopédia Histórico-Teológica da Igreja Cristã. São Paulo: Vida Nova, 1988. v. I, p. 202.

15 OLIVER Jr., Guy. Cátaros. In: Enciclopédia Histórico-Teológica da Igreja Cristã. São Paulo: Vida Nova, 1988. v. I, p. 246. 
de uma vida completamente dirigida pelos desejos e decisões dos outros - pais, irmãos, esposos e filhos ${ }^{16}$.

Os begardos eram os correspondentes masculinos das beguinas. Já os flagelantes surgiram no século XIII e experimentaram expansão no século seguinte. Como o próprio nome indica, eram pessoas do povo (não religiosos em mosteiros) que se chicoteavam até sangrar, não como um ato histérico, mas como resultado de uma disciplina espiritual muito rígida e tentativa de viver mais perto de Deus. O movimento foi perseguido porque as autoridades eclesiásticas da época entendiam que eles pregavam uma salvação à parte da estrutura oficial da igreja, sem qualquer mediação sacerdotal. ${ }^{17}$

A respeito dos movimentos medievais de busca espiritual e tentativa de revitalização e/ou reforma, das vidas dos crentes e das estruturas eclesiásticas, os historiadores Felipe Fernandez-Armesto e Derek Wilson anotaram, com uma prosa elegante, mas na qual se percebe certa dose de ironia:

A Igreja Hussita, na Boêmia, precedeu as igrejas nacionais da era da Reforma de uma maneira surpreendente: a doutrina católica da eucaristia foi abjurada; eram ministrados os dois elementos da eucaristia; a liturgia era celebrada na língua vernácula. As propriedades da Igreja foram secularizadas; a unidade da Igreja Reformada foi dissolvida, por sua vez, entre as tendências dissidentes.

Também houve precedentes ainda mais antigos. Não está claro o que havia de distinto, em termos doutrinários, na Igreja da Bósnia do século XIV (se é que havia alguma distinção), mas este foi um caso nítido de secessão de uma província bem definida para com a Igreja Católica. No início do século XV, o Estado inglês foi quase usurpado por adeptos das heresias de John Wycliffe, o lente de Oxford que os protestantes, posteriormente, consideraram seu antecessor. No século XII, a heresia cátara - que em geral, mas sem convicção, se supõe ter sido uma forma de dualismo - chegou perto de se constituir em uma igreja oficial nas terras dos condes de Toulouse. No século X, a Bulgária tinha sua própria igreja, dedicada à heresia do padre Bogomil - uma fé pretensamente dualista com a qual os primeiros cátaros podem ter tido contato ${ }^{18}$.

Movimento de busca espiritual que conseguiu sobreviver aos nossos dias é o dos valdenses, considerados como uma espécie de protoprotestantismo. O movimento valdense está ligado à figura de Pierre Valdo, comerciante de Lyon, no fim do século XI. Sua leitura de Mc 10.21 - "vai, vende tudo o que tens, dá o dinheiros aos pobres e terás um tesouro no céu" (Edição da CNBB) - foi literal. Após ter vendido seus bens e distribuído o produto da venda aos pobres de sua cidade, tornou-se um pregador itinerante. Valdo defendeu ideias que seriam proclamadas por Lutero séculos depois, como a divulgação do estudo bíblico para todos os fiéis e a rejeição de imagens no cul-

${ }^{16}$ GONZALEZ, Justo. A era dos sonhos frustrados. 2. ed. São Paulo: Vida Nova, 1986. p. 21. (Uma história ilustrada do cristianismo, v. 5).

${ }^{17}$ GONZALEZ, 1986, v. 5, p. 116-118.

18 FERNANDEZ-ARMESTO, Felipe; WILSON, Derek. Reforma. O Cristianismo e o mundo. 1500-2000. Rio de Janeiro: Record, 1997. p. 18-19. 
to. Perseguidos, os membros do movimento, que ficaram conhecidos como valdenses, refugiaram-se fora das cidades. Famílias de seguidores dos ensinos de Valdo fugiram para a região montanhosa do Piemonte, na Itália, o que explica a virtual inexistência de valdenses franceses e o grande número de italianos que aderiu ao movimento. Os valdenses queriam resgatar o vigor e a simplicidade da ecclesia primitiva. Por levarem às últimas consequências a pobreza evangélica no seguimento de Jesus (como mais tarde enfatizaria Francisco de Assis), os valdenses foram conhecidos como nudi nudum Christum sequentes, "seguidores nus de um Cristo nu"19. Mais tarde, com o advento do protestantismo, os valdenses são acolhidos na então nascente igreja reformada de linha calvinista, no Sínodo de Chanforan, nos arredores de Torre Pellice, na citada região piemontesa, em 1532. Surge então a Chiesa Evangelica Valdese, a Igreja Evangélica Valdense. ${ }^{20}$ Imigrantes italianos identificados com a tradição valdense levaram a igreja para o Cone Sul, organizando a Iglesia Evangélica del Rio de la Plata, uma espécie de igreja de síntese entre reformados (imigrantes italianos valdenses) e luteranos (imigrantes de origem germânica). Essa igreja está presente na Argentina, no Uruguai e no Paraguai. ${ }^{21}$

As ordens mendicantes católicas também foram expressões de movimentos de busca espiritual na Idade Média. Dessas, as mais famosas são sem dúvida a Ordem dos Frades Menores e a Ordem dos Pregadores, conhecidos popularmente respectivamente como franciscanos e dominicanos, em homenagem aos seus fundadores, Francisco de Assis e Domingos de Gusmão. ${ }^{22} \mathrm{O}$ objetivo desses movimentos era a revitalização do cristianismo de seu tempo. Particularmente interessante é o movimento da Ordo Fratrum Minorum, nome extraído do texto da Vulgata de Mt 25.40: os fratribus meis minimis ${ }^{23}$ ("meus irmãos mais pequeninos", BJ), que devem ser alvo de especiais atenção e amor - caritas - da parte dos cristãos, por, ao mesmo tempo, revelarem e ocultarem o Cristo. Francisco ${ }^{24}$, com sua espiritualidade cristocêntrica e sua "evangelicidade" radical, antecipou algumas ênfases que desabrochariam, grosso modo, trezentos anos depois no movimento de Lutero. Uma dessas ênfases é a do papel dado aos assim chamados leigos, com a criação das Ordens Terceiras. Essa ênfase encontrará especial destaque em Lutero, com sua doutrina do sacerdócio universal de todos os crentes. ${ }^{25}$ Lutero será seguido nessa ênfase por Calvino e por todos os demais reformadores.

${ }^{19}$ GEORGE, 1994, p. 41.

${ }^{20}$ Para detalhes, consultar: <http://www.chiesavaldese.org >. Acesso em: 14 out. 2016.

${ }^{21}$ Para detalhes, consultar: <http://www.ierp.org.ar/>. Acesso em: 14 out. 2016.

22 Além dessas, também são contadas entre as ordens mendicantes a Ordem do Carmo (carmelitas) e a Ordem de Santo Agostinho (agostinianos). Cf. BISHOP, Russell K. Ordem Franciscana. In: ELWELL (Org.), 1990, v. III, p. 62.

${ }^{23}$ Disponível em: <http://www.bibliacatolica.com.br/vulgata-latina/evangelium-secundum-matthaeum/25/>. Acesso em: 15 out. 2016.

${ }^{24}$ É vasta a bibliografia a respeito de Francisco e do movimento que iniciou. Para biografias críticas de Francisco, consultar, inter alia, LE GOFF, Jacques. São Francisco de Assis. São Paulo: Record, 2001. SPOTO, Donald. Francisco de Assis: o santo relutante. Rio de Janeiro: Objetiva, 2003.

${ }^{25}$ Para o tratamento do próprio Lutero ao tema do sacerdócio universal de todos os crentes ver os artigos 16 e 17 de LUTERO, Martinho. Da liberdade do cristão. Edição bilíngüe. 2. ed. São Paulo: Editora da UNESP, 1997. p. 43-45. 
Particularmente interessante nesse estudo da contribuição dos Frades Menores ao grande movimento de busca espiritual medieval, que, conforme já afirmado, encontrou pleno cumprimento no século XVI, com as reformas protestante e católica, foi o surgimento do grupo conhecido como "franciscanos espirituais" (em contraste com os franciscanos conventuais). Os "espirituais" formaram um movimento interno de renovação e revitalização do carisma franciscano original. Para tanto, buscaram resgatar a radicalidade da proposta de pobreza absoluta do próprio Francisco e foram influenciados pela filosofia da história de Joaquim de Fiore (1132-1202). Conforme de Fiore, a história é dividida em três eras, correspondentes às pessoas da Trindade. Esperava-se a Terceira Era, a Era do Espírito Santo, que superaria a era em que a igreja era dona de riquezas, poder, prestígio e influência. A Era do Espírito traria consigo o milênio de paz, fartura e solidariedade para os seres humanos. Alguns dos franciscanos espirituais foram muito contundentes em sua crítica às autoridades eclesiásticas de seu tempo. A reação da igreja foi implacável: “em 1318, quatro espirituais foram julgados pela Inquisição e queimados vivos em Marselha"26.

Enquanto esses movimentos de busca espiritual e reforma e/ou revitalização da igreja têm lugar no continente, o mesmo acontece na Inglaterra. Já no século XIV encontra-se o já mencionado, posto que en passant, John Wycliffe (1328-1384; seu nome algumas vezes aparece grafado como Wiclif ou ainda como Wycliff) na Inglaterra, que a historiografia protestante posterior denominou, de maneira poética, "A Estrela d'Alva da Reforma". Wycliffe, que fora professor de teologia na já então prestigiosa Universidade de Oxford, foi crítico cáustico das estruturas eclesiásticas de seu tempo e de suas respectivas lideranças. Antecipando o Sola Scriptura de Lutero em mais de um século, Wycliffe traduz a Bíblia para o inglês, utilizando a Vulgata como base de seu trabalho. Wycliffe rejeita a visão transubstancionista tradicional da eucaristia, sendo por isso demitido de seu cargo de lente em Oxford em 1381. A visão que ele adota, qual seja, da presença de Cristo com os elementos pão e vinho, será muito semelhante à adotada por Lutero mais tarde, conhecida na história do pensamento cristão como consubstanciação. A respeito de Wycliffe foi dito:

John Wiclif se opôs, no século XIV, aos teólogos da assim chamada via moderna e ao tomismo. As doutrinas de Wiclif interessam-nos aqui como expressão histórica do pensamento religioso medieval e na medida em que conduzem a um rompimento do universalismo sonhado tanto por canonistas quanto por legistas. O seu retorno a uma posição fundamentalmente platônico-agostiniana teria sequência no pensamento de Huss e, posteriormente, de Lutero [...] Wiclif é o ponto de confluência das múltiplas insatisfações de sua época e de seu povo ${ }^{27}$.

${ }^{26}$ GEORGE, 1994, p. 40.

${ }^{27}$ SCHÜLLER, Osvaldo. John Wiclif e a dissolução do universalismo medieval. Canoas: ULBRA, 2002. p. 14-15. 
Wycliffe encarregou um grupo de sacerdotes ingleses como pregadores itinerantes. Esses pregadores, conhecidos como Poor Preachers ("Pregadores pobres"), ficaram mais conhecidos como lolardos. A etimologia da palavra é incerta:

Lolardo: nome de certos grupos heréticos do fim do século XIV; também Loller, do Médio Holandês lollaerd, palavra aplicada pejorativamente a seitas reformistas semimonásticas ativas nos Países Baixos desde cerca de 1300, que se devotavam ao cuidado dos doentes e dos pobres. A palavra holandesa significa literalmente "reclamador, resmungador, alguém que murmura orações e hinos", de lollen, "murmurar ou dormitar"28.

Quanto às crenças do movimento, sabe-se, a partir da leitura do documento intitulado As Doze Conclusões dos Lolardos, de 1394, uma espécie de declaração de fé daqueles seguidores de Wycliffe, que rejeitavam a posse de riquezas da parte da igreja, da Inglaterra e de Roma (Primeira Conclusão), negavam o celibato clerical (Terceira Conclusão), negavam a transubstanciação (Quarta Conclusão), valorizavam o serviço "espiritual” em serviços seculares (e não no claustro ou no convento, Sexta Conclusão), negavam a validade das orações pelos mortos (Sétima Conclusão), e rejeitavam a violência da guerra, das batalhas e das Cruzadas, por ser algo "expressamente contrário ao Novo Testamento, que é a lei da graça, e pleno de misericórdia" (Décima Conclusão ${ }^{29}$ ). Quanto ao destino dos lolardos, o historiador cubano Justo Gonzalez afirmou:

Apesar de serem perseguidos constantemente, os lolardos nunca foram totalmente extintos. Em princípios do século XVI o movimento recobrou forças, e o número de mártires executados por defender suas doutrinas aumentou consideravelmente. Mais tarde, o remanescente lolardo, que deve ter sido considerável, se misturou com os primeiros protestantes. Por isto, apesar de os sonhos de Wycliff e de seus primeiros seguidores serem temporariamente frustrados, a longo prazo eles se concretizaram na grande Reforma que comoveu a Inglaterra e toda a Europa no século XVI ${ }^{30}$.

Outro exemplo de "protestantismo avant la lettre" é de Jan Hus (ou Huss, 1369-1415), na Boêmia, região do que é atualmente a República Checa. Hus foi profundamente influenciado por Wycliffe. Entre outras coisas, Hus ensinava a ineficácia das indulgências no processo da salvação humana. Seus sermões criticavam o baixo nível moral do clero de seu tempo, eram marcados por forte ênfase cristocêntrica, enquanto ao mesmo tempo adotava a doutrina católico-romana tradicional do purga-

${ }^{28}$ Lollard: name for certain heretics, late 14c., also Loller, from Middle Dutch lollaerd, a word applied pejoratively to members of semi-monastic reforming sects in the Low Countries from c. 1300 who devoted themselves to the care of the sick and poor. The Dutch word means literally "mumbler, mutterer", one who mutters prayers and hymns", from lollen "to memble or doze". Online Etymology Dictionary. Disponível em: <http://www.etymonline.com/index.php?term=Lollard>. Acesso em: 29 out. 2016.

29 Disponível em: <http://sites.fas.harvard.edu/ chaucer/special/varia/lollards/lollconc.htm>. Acesso em: 29-30 out. 2016. Para uma versão em português dessa declaração de fé dos lolardos, cf. BETTENSON, Harry. Documentos da igreja cristã. 3. edi São Paulo: ASTE, 1998. p. 268-274.

${ }^{30}$ GONZALEZ, 1986, v. 5, p. 91. 
tório. ${ }^{31}$ Sua obra, intitulada De Ecclesia, foi profundamente influente na trajetória de Lutero. ${ }^{32}$ Hus teve fim trágico:

Em 1414, com a promessa de salvo-conduto, Hus viajou para o Concílio de Constança, onde foi preso e julgado por heresia. Recusou-se a reconhecer que as acusações contra ele fossem verídicas, a não ser que fossem comprovadas pelas Escrituras. Mesmo assim, foi condenado como culpado e queimado à estaca, em 6 de julho de $1415^{33}$.

O movimento iniciado por Hus deixou "descendentes", como os taboritas, um grupo com tendências apocalípticas. Os taboritas eram um grupo rural, interiorano, formado em sua maioria por pessoas pobres, e em suas ideias eram mais radicais que os hussitas. Criam na proximidade do fim dos tempos e na irrupção iminente do reino de Deus na terra. A manifestação do Reino não seria uma vitória dos oprimidos contra os opressores, mas dos santoscontra os pecadores. Só que na compreensão dos taboritas, "pecadores" eram os ricos, comerciantes abastados e proprietários de terras que viviam no luxo e na abastança. Para os taboritas, tudo que não estivesse explicitamente nas Escrituras deveria ser abolido. Logo, rejeitaram vestes clericais, cerimônias tradicionais e ornamentos nas igrejas. $\mathrm{O}$ fato de pertencerem a extratos socioeconômicos mais baixos da população provavelmente explica algumas de suas radicalidades. ${ }^{34}$

Outro movimento de inspiração hussita foi o grupo conhecido como Unitas Fratrum, "Unidade dos irmãos":

Esta organização chegou a ser numerosíssima, não somente na Boêmia, mas também na Morávia. Durante a reforma do século XVI eles estabeleceram estreitas relações com o protestantismo, e por algum tempo pensou-se que eles se juntariam aos luteranos. Pouco depois os imperadores da casa da Áustria, que davam todo seu apoio ao catolicismo, começaram a persegui-los. A organização foi praticamente destruída. Mas o bispo João Amós Comênio, do exílio, continuava animando-os e intercedendo por eles ${ }^{35}$.

Esses exemplos são suficientes para mostrar como mais de cem anos antes de Lutero havia o que pode ser chamado de "protestantismo antes do protestantismo".

Depois dessa apresentação, posto que panorâmica, mas necessária, da trajetória da compreensão de espiritualidade, da tradição da teologia mística ocidental, e de alguns exemplos de movimentos de busca espiritual e de revitalização da fé no período medieval ocidental, é chegado o momento de explicitar um pressuposto da pesquisa, qual seja, que seus objetos de estudo, a saber, Loyola e Calvino, foram, em maior ou menor extensão e grau, influenciados pelo movimento conhecido como Devotio moderna (literalmente, "devoção moderna"). Em outras palavras: de tempos

${ }^{31}$ Cf. KUBRICHT, Paul. Hus, João. In: ELWELL (Org.), 1990, v. II, p. 280-281.

32 GEORGE, 1994, p. 38.

33 KUBRICHT, 1990, p. 280.

34 GONZALEZ, 1986, v. 5, p. 104, 118.

35 GONZALEZ, 1986, v. 5, p. 108. João Amós Comênio é a forma aportuguesada de Jan Amos Komensky (1592-1670), bispo protestante de inspiração hussita, tido como o pai da didática moderna. 
em tempos houve, em todo o decorrer da história do cristianismo, a manifestação de um movimento de retorno às origens, de resgate da força original do movimento dos seguidores de Jesus. Essa busca por revitalização não acontece pela primeira vez no século XVI. É possível apontar para diversos movimentos marcados por essa busca de restauração. Um desses é a Devotio moderna. Por conta da importância desse movimento para a compreensão, tanto da Reforma Protestante como também da Reforma Católica (da qual Loyola foi elemento fundamental) no século XVI, esse movimento será apresentado no próximo subitem. Pois “[...] os reformadores - protestantes, católicos e radicais semelhantemente - foram capazes de suas realizações porque estavam sensíveis às mais profundas lutas e esperanças de sua época"36.

\section{A Devotio moderna}

A preocupação com a revitalização dos propósitos de fidelidade e amor a Deus e aprofundamento da experiência de fé sempre esteve presente no cristianismo. De tempos em tempos surgem movimentos que propõem essa oxigenação e renovação da vida de fé, para que ela não se reduza a mero formalismo ritual ou repetição mecânica de fórmulas litúrgicas ou confessionais. ${ }^{37} \mathrm{E}$, como se verá na sequência, o fim da Idade Média foi marcado por movimentos de piedade e aprofundamento da vida com Deus. $\mathrm{Na}$ verdade, a Idade Média como um todo foi marcada pela virtual onipresença de uma sensibilidade quanto ao transcendente, e uma busca do mesmo. Nas palavras do historiador francês Marc Bloch, um dos fundadores da École des Annales:

Os homens da Idade Média, ou pelo menos, a imensa maioria deles, tinham das coisas da religião uma imagem muito material e, se se pode dizer, extremamente terra-a-terra. Como poderia ser de outra forma? A seus olhos, não havia um abismo intransponível entre o mundo em que viviam e o mundo do maravilhoso para o qual os ritos cristãos abriam a porta; os dois universos penetravam-se mutuamente $[\ldots]^{38}$.

Em outras palavras: na cultura e na sociedade medievais, o transcendente e o imanente estavam muito mais próximos do que acontece em ambientes secularizados. E já há muito tempo existia no Ocidente um desejo de que o relacionamento com o transcendente cristão não fosse apenas ritual, mas expressão de sinceridade do coração. Nesse sentido, diferentes movimentos propuseram uma revitalização da vivência da fé. Um desses foi a Devotio moderna:

${ }^{36}$ GEORGE, 1994, p. 21.

37 Uma lenda sobre Isaque de Odessa diz que ele tinha um papagaio que recitava o Trisagion na praça do mercado. A essência da fé cristã é que toda fórmula litúrgica ou confissão de fé seja proferida com sinceridade do coração, e não como mera repetição mecânica irrefletida, para que não seja mera confissão de papagaio...

38 BLOCH, Marc. Os reis taumaturgos. O caráter sobrenatural do poder régio. França e Inglaterra. São Paulo: Companhia das Letras, 1993. p. 81. 
A Devotio moderna, literalmente, "Devoção moderna", foi o movimento religioso mais bem-sucedido na Idade Média tardia na Europa. Tinha como propósito a reforma da vida espiritual conforme os ideais do cristianismo primitivo, e era caracterizado pela busca de uma intensa vida espiritual interior. Desde seu início na Holanda, irradiou-se para o sul, até o todo da Europa ocidental e ao longo da rede de cidades hanseáticas do norte da Europa. O centro geográfico da Devotio moderna incluía o nordeste dos Países Baixos, a Vestefália e a parte baixa do Reno, onde no primeiro terço do século XV onde era praticada, acima de tudo, em comunidades de Irmãs devotas, em fundações afiliadas diretamente a Meester-Geertshuis ${ }^{39}$ e Herr-Florenshuis em Deventer, que foram as casas-mãe dos ramos masculino e feminino para reforma espiritual ${ }^{40}$.

A Devotio moderna foi um movimento de motivação para a vida consagrada, mas na sociedade, não no claustro. Logo, era um movimento leigo, não clerical. Quanto a isso, McGrath afirma:

A relação bastante próxima entre a educação e a piedade leiga na Baixa Idade Média pode ser observada no fato de o crescimento extraordinário do interesse na educação no final do século 15 ter sido associado, em primeiro lugar, a instituições monásticas, especialmente àquelas dedicadas à devotio moderna. Os Irmãos da Vida Comum ocupam uma posição estratégica tanto em termos históricos quanto teológicos, pois é possível argumentar que sua concepção diferenciada da natureza da vida religiosa ficava entre a clausura e o mundo, engendrando valores e atitudes que podem ser tidos como características da transição do período medieval para o moderno. A devotio moderna pode ser considerada a espiritualidade distinta associada à ordem que serviu de base para seus projetos de educação e reforma monástica. Ainda que, a princípio, a devotio moderna não se preocupasse, fundamentalmente com a educação popular, mas com a reforma dos mosteiros, não tardou em assumir um papel pedagógico de grande importância no século 15. Os albergues estudantis anexos aos principais mosteiros dos Irmãos da Vida Comum ampliaram seu interesse no bem-estar pastoral de seus alunos de modo a incluir sua educação. Inevitavelmente, a piedade da devotio moderna foi transmitida neste processo educativo. No final do período medieval, o programa educacional monástico resultou, para os leigos, numa consciência cada vez maior dos rudimentos de uma tradição espiritual devidamente fundamentada, bem como dos elementos da gramática do latim ${ }^{41}$.

Evidência da laicidade da Devotio moderna encontra-se no próprio nome Irmãos da Vida Comum, o movimento iniciado pelo citado Geert Groot, que "em 1379 foi consagrado como diácono e, embora nunca fosse ordenado sacerdote, tornou-se

39 Meester-Geertshuis significa "Casa do Mestre Geert” em holandês, uma entidade ligada a Geert Groot (1340-1384), fundador do movimento dos Irmãos da Vida Comum, de grande importância na Devotio moderna. A Meester-Geertshuis funciona até hoje em Deventer, ligada à Igreja Reformada da Holanda. Para informações: <http://www.meestergeertshuis.nl/>. Acesso em: 17 set. 2016. A Herr-Florenshuis foi nomeada em homenagem a Florens Radewijns, outro nome destacado da Devotio moderna.

40 BOLLMANN, Anne. The Influence of Devotio moderna in Northern Germany. ANDERSEN, Elizabeth; LÄHNEMANN, Henrike; SIMON, Anne. A Companion to Mysticism and Devotion in Northern Germany in the Late Middle Ages. Leiden: Brill, 2014. p. 231. (tradução nossa).

${ }^{41}$ McGRATH, 2007, p. 22. 
um pregador missionário na diocese de Utrecht [...] em seus sermões escritos, Groote ressaltava a pobreza, a vida comunitária (mas não enclausurada), o compromisso com Cristo e a necessidade de a igreja estar presente no mundo"42. Percebem-se pontos de contato entre o movimento dos Irmãos da Vida Comum e as irmandades de ordens terceiras de inspiração franciscana por conta de sua ênfase nos cristãos "leigos". Uma síntese do movimento da Devotio moderna é apresentada por Peter H. Davids:

A Devotio Moderna era fortemente agostiniana no seu tom, mas sem a ênfase que Agostinho dava à predestinação. As marcas principais do movimento incluíam: (1) um enfoque na devoção a Cristo, incluindo a meditação sobre a sua paixão; (2) uma ênfase à obediência aos mandamentos de Cristo e, portanto, à santidade, simplicidade e comunidade; (3) um nítido envolvimento na piedade individual e na vida espiritual; (4) uma chamada ao arrependimento e à reforma; e (5) elementos do nominalismo, do humanismo cristão e do ascetismo franciscano.

Os seguidores do movimento tinham uma ênfase bíblica, estimulavam o ministério leigo, o relacionamento pessoal com Cristo e a rejeição das indulgências e de outros abusos medievais, de modo que pareciam precursores dos reformadores ${ }^{43}$.

O movimento dos Irmãos da Vida Comum seguia a piedade da Devotio moder$n a$, centralizada na meditação sobre a vida de Cristo e no discipulado cristão. Quanto aos Irmãos da Vida Comum o historiador J. D. Douglas afirmou:

Os membros não faziam votos, não se filiavam a ordem religiosa alguma, mas procuravam viver na presença de Deus uma vida de dedicação e total e preparar-se para a vida eterna. Contudo, além disso, essa linha mística foi complementada de modo saudável pela filantropia ativa com os pobres e o estabelecimento de albergues para estudantes. A partir daí desenvolveram-se algumas das melhores escolas no século XV. Entre aquelas que receberam benefícios do treinamento pelos Irmãos esteve Erasmo, o maior humanista dos seus tempos (sic) ${ }^{44}$.

A mais importante obra representativa dessa tradição é Imitação de Cristo, de Thomas a Kempis (ou Tomás de Kempis), um dos mais importantes textos de espiritualidade cristã de todos os tempos. Alister McGrath explica:

A relação bastante próxima entre a educação e a piedade leiga na Baixa Idade Média pode ser observada no fato de o crescimento extraordinário do interesse na educação no final do século 15 ter sido associado, em primeiro lugar, a instituições monásticas, especialmente aquelas dedicadas à devotio moderna. Os Irmãos da Vida Comum ocupam uma posição estratégica tanto em termos históricos quanto teológicos, pois é possível argumentar que sua concepção diferenciada da natureza da vida religiosa ficava entre a clausura e o mundo, engendrando valores e atitudes que podem ser tidos como características da transição do período medieval para o moderno. A devotio moderna pode ser

${ }^{42}$ DOUGLAS, J. D. Groote, Gerard. In: ELWELL (Org.), 1990, v. II, p. 229.

43 DAVIDS, Peter H. Devotio Moderna. In: ELWELL (Org.), 1990, v. II, p. 452.

44 DOUGLAS, J. D. Irmãos da Vida Comum. In: ELWELL (Org.), 1990, v. II, p. 347. 
considerada a espiritualidade distintiva associada à ordem, que serviu de base para seus projetos de educação e reforma monástica. Ainda que, a princípio, a devotio moderna não se preocupasse, fundamentalmente, com a educação popular, mas com a reforma dos mosteiros, não tardou em assumir um papel pedagógico de grande importância no século 15. Os albergues estudantis anexos aos principais mosteiros dos irmãos da Vida Comum ampliaram seu interesse no bem-estar pastoral de seus alunos de modo a incluir sua educação. Inevitavelmente, a piedade da devotio moderna foi transmitida neste processo educativo. No final do período medieval, o programa educacional monástico resultou, para os leigos, numa consciência cada vez maior dos rudimentos de uma tradição espiritual devidamente fundamentada, bem como dos elementos da gramática do latim $^{45}$.

A ênfase no entendimento da vida cristã como imitatio Christi, típica da Devotio moderna, terá grandes repercussões na Reforma Protestante, influenciando, por exemplo, pensadores identificados com o então nascente protestantismo, como o francês Martin Bucer, líder reformado em Estrasburgo, tendo naquela cidade acolhido Calvino durante os três anos em que este esteve expulso de Genebra. ${ }^{46}$ Essa influência se estenderá pelos séculos seguintes: no século XX Dietrich Bonhoeffer, em Discipulado e Vida em comunhão, duas de suas principais obras de cunho devocional, demonstrará ter sido decisivamente influenciado por Imitação de Cristo de Kempis que, como afirmado, é a obra que melhor representa a piedade da Devotio moderna do fim da Idade Média. ${ }^{47}$

A Imitação de Cristo é um dos textos devocionais cristãos mais conhecidos e lidos de todos os tempos. Logo no seu início, o texto argumenta a favor da superioridade do temor e amor a Deus em relação ao mero conhecimento teórico ou especulativo dos conteúdos da fé cristã:

3. Que te aproveita discorrer profundamente sobre a Santíssima Trindade, se não és humilde, e por isso à Trindade desagradas? Em verdade as palavras sublimes não fazem o homem santo e justo; é a vida pura que o torna querido de Deus. Prefiro sentir compunção a saber-lhe a definição. Se souberas toda a Bíblia de cor e todas as máximas dos filósofos, que te aproveitaria tudo isto sem o amor e a graça de Deus? Vaidade das vaidades é tudo vaidade, (Eccles. [Sic] I, 12), exceto o amor a Deus e só a Ele servir. A verdadeira sabedoria consiste em tender para o reino do céu pelo desprezo do mundo ${ }^{48}$.

Esse trecho bem resume o espírito da Imitação, pois expressa bem a compreensão de vida cristã do final da Idade Média. O historiador Dennis D. Martin apresenta uma síntese útil do conteúdo da Imitação:

${ }^{45}$ McGRATH, 2007, p. 22.

${ }^{46}$ McGRATH, 2007, p. 158.

${ }^{47}$ Cf. FRICK, Peter. The Imitatio Christi of Thomas à Kempis and Dietrich Bonhoeffer. In: FRICK, Peter (Org.). Bonhoeffer's Intellectual Formation. Tübingen: Mohr Siebeck, 2008. p. 31-52.

${ }^{48}$ Kempis, Tomás de. Imitação de Cristo. Tradução do Pe. Leonel Franca, SJ. Rio de Janeiro: José Olimpio Editora, 1944. Disponível em: $<$ http://www.monergismo.com/textos/vida_piedosa/imitacao_cristo.htm>. Acesso em: 20 set. 2016. 
[...] diferentemente da espiritualidade semi-monástica dos Irmãos da Vida Comum, que procuravam viver vidas devotas no meio das cidades movimentadas, o ensino espiritual da Imitação enfatiza a fuga das distrações e dos perigos do mundo. Adverte contra a confiança em nossa própria prudência e conclama ao conhecimento de nós mesmos, à contínua autocrítica, e as outras virtudes monásticas tradicionais. Critica, também, a teologização especulativa, e prefere o estudo que inflama o coração com amor a Deus. O primeiro tomo é uma coletânea (rapapiarium) de meditações espirituais; o segundo e o terceiro tomo, o coração da Imitação, oferecem conselhos sobre o crescimento nas virtudes tais como a humildade, a paciência e a obediência, e sobre as flutuações da vida interior. $\mathrm{O}$ quarto tomo dedica-se à piedade eucarística ${ }^{49}$.

Uma compreensão do espírito da Imitação será influente, conforme já afirmado, nos desdobramentos históricos posteriores, entre esses, as reformas religiosas do século XVI, a protestante e a católica. Não será exagero afirmar que a Devotio moderna influenciou todo o pensamento religioso do século XVI no que diz respeito à busca de uma intensidade de vida de comunhão com Deus, o que vale dizer que Calvino e Loyola foram influenciados por esse movimento. Nesse sentido, também não será exagero afirmar que, com sua ênfase no estudo bíblico e na comunhão com Deus, a Devotio moderna era um movimento de reforma pré-Reforma. O citado historiador Dennis Martin insinua que a Devotio foi de certa forma superada e suplantada pela Reforma Protestante. ${ }^{50}$ Pode ser que haja um tanto de exagero em sua conclusão. Talvez seja mais razoável dizer que a Devotio pavimentou o caminho para as reformas religiosas do século XVI, que fez surgir o protestantismo, e a acontecida no seio da Igreja Católica. Daí a importância de conhecer a Devotio moderna. Em seu tempo, ela foi um movimento que permaneceu inteiramente dentro da estrutura organizacional da Igreja Católica. Mas Groote e seus seguidores jamais tiveram intenção de criar outro corpo eclesiástico, da mesma forma como Lutero, mais de cem anos depois, também não tinha essa intenção. ${ }^{51} \mathrm{O}$ que a Devotio propunha era o mesmo que os reformadores protestantes e os místicos católicos do século XVI pretendiam, ou seja, uma sinceridade de vida pessoal com Deus, alimentada pelo estudo bíblico e vivenciada em uma piedade cristocêntrica.

Conclui-se, então, que a Devotio de certa forma sobreviveu no pensamento da Reforma Protestante, no sentido de que a doutrina luterana (mais tarde adotada pelos demais reformadores) do sacerdócio universal dos crentes (ou dos fiéis, ou dos santos) não foi uma "invenção" de Lutero, mas uma ideia já defendida e praticada por

49 MARTIN, Dennis D. Tomás de Kempis. In: ELWELL (Org.), 1990, v. III, p. 543.

${ }^{50}$ MARTIN, 1990, p. 543.

${ }^{51}$ A saída de Lutero da Igreja Católica se deu como circunstância natural e até mesmo inevitável, após ele ter recebido uma ameaça de excomunhão pelo papa Leão X, através da Bula Papal Exsurge Domine ("Levanta-te, Senhor", extraído do texto da Vulgata de Nm 10.35), de 15 de junho de 1520, na qual o papa concedia-lhe 60 dias para se retratar. Findo esse período, Lutero queimou publicamente a bula papal e tomos de direito canônico. A excomunhão de Lutero propriamente se deu pouco mais tarde, em 03 de janeiro de 1521, através de Decet romanum pontificem, bula que, curiosamente, não se tornou conhecida como a anterior. Em 26 de maio de 1521, o imperador Carlos V baniu Lutero, tornando-o assim oficialmente um proscrito. 
grupos cristãos no fim da Idade Média, notadamente a Devotio moderna. Mas não se pode esquecer do mencionado anteriormente, posto que en passant, que tal ênfase no ministério ativo dos "leigos" tem inspiração ainda mais antiga, pois tem raiz no movimento das ordens terceiras de inspiração franciscana.

Outro aspecto da Devotio moderna que sobreviveu, por assim dizer, no movimento da Reforma Protestante foi a ênfase na piedade pessoal inspirada no seguimento de Cristo, no estudo bíblico e na busca de serviço ao próximo como manifestação de serviço a Deus no "mundo". Essas ênfases da Devotio, tal como afirmado acima, prepararam o caminho tanto para o movimento reformista iniciado por Lutero - que influenciou decisivamente Calvino, um dos objetos de estudo desta pesquisa - como também o movimento de reforma dentro da Igreja Católica, que tem como uma de suas principais referências Inácio de Loyola, o outro objeto de estudo da pesquisa. Quanto a este último, não se pode esquecer que ele foi influenciado pela reforma na igreja espanhola liderada pelo cardeal Francisco Jiménez (ou Ximenez) de Cisneros (1436-1517). "Cisneros era um frade franciscano em quem se combinavam a pobreza e a austeridade franciscanas com o humanismo erasmista. Antes de ser arcebispo, havia dado amplas provas tanto de seu temperamento como de sua erudição" 52 . Os textos de Cisneros demonstram ter ele recebido influência da Devotio moderna. ${ }^{53}$ Cisneros foi conselheiro espiritual da rainha Isabel da Espanha, que lhe deu todo apoio em seu projeto de reforma do clero espanhol da época (em situação de baixo nível moral, intelectual e espiritual virtualmente idêntica àquela contra qual Lutero protestou mais tarde na Alemanha). Elementos importantíssimos no projeto de reforma de Cisneros foram a Bíblia Poliglota Complutense (com textos em colunas, em hebraico, grego e latim) e a organização da Universidade de Alcalá. "O propósito de Cisneros era que aquele centro docente se tornasse o núcleo de uma grande reforma da igreja e da vida civil espanhola. E esse sonho se cumpriu, pois entre os que estudaram no famoso plantel se encontram Miguel de Cervantes, Inácio de Loyola e João Valdez"54. Conclui-se assim que a sede de reforma espiritual no período imediatamente anterior ao do tempo da Reforma Protestante também aconteceu na península Ibérica (e não apenas no norte da Europa ou nas Ilhas Britânicas), e que a Devotio moderna foi mais influente nas propostas da Reforma do século XVI do que normalmente se diz em abordagens populares ao tema (e até mesmo algumas que se pretendem acadêmicas).

Assim conclui-se que a busca por "reforma", na vida da igreja enquanto instituição e nas vidas dos fiéis, sempre esteve presente na história do cristianismo ocidental. De fato, o próprio Lutero afirmou:

Durante mais de um século os homens já vinham falando em reforma, mas eu a realizei. Pela graça de Deus, efetuei uma mudança de forma a [...] estabelecer a ordem correta para todas as camadas da sociedade, de maneira que cada uma saberá como viver e ser-

\footnotetext{
${ }^{52}$ GONZALEZ, 1983, v. 6, p. 24-25.

${ }^{53}$ HOUSTON, James. Espiritualidade. In: ELWELL (Org.), 1990, v. II, p. 65.

${ }^{54}$ GONZALEZ, 1983, v. 6, p. 28.
} 
vir a Deus segundo o papel que lhe cabe. E para aqueles que a aceitaram, minha reforma trouxe não um pequeno benefício, mas paz e virtude ${ }^{55}$.

\section{Considerações finais}

O ponto até o momento apresentado neste artigo, isto é, a influência dos movimentos conhecidos grosso modo como pré-Reforma em Lutero e, por extensão, nos demais reformadores propriamente, é consensual entre os historiadores. Um desses, o brasileiro Martin N. Dreher, anotou:

[...] a Idade Média está plena de movimentos de reforma. Nos séculos XI, XII e XIII a Itália e o Sul da França foram sacudidas por movimentos reformatórios que ansiavam pela pobreza apostólica e, concomitantemente, criticavam a Igreja rica, sem vida. Nesses movimentos, o grito por reforma era chamado à penitência, conversão à vida do Cristo pobre. Alguns desses grupos reformistas foram terrivelmente massacrados. Basta que citemos os nomes dos albigenses e dos valdenses. Os ideais desses movimentos só puderam ser submetidos ao controle da Igreja oficial, quando os papas aprovaram as ordens mendicantes. Nelas o ideal de pobreza pôde ser exercido dentro da Igreja, vicariamente, substitutivamente, no lugar dos ricos prelados e ricos leigos ${ }^{56}$.

Nessa mesma linha, Eduardo Hoornaert, historiador flamengo radicado no Brasil, apontou:

Particularmente a Idade Média foi uma época fervilhada de movimentos heréticos, quase todos abafados desde o início ou recuperados pela ortodoxia. São os bogomitas da Rússia, os cátaros do sul da França, os albigenses, valdenses, primeiros franciscanos, umiliati, joaquimistas, espirituais, fraticelli, beguinas e lolardos, hussitas. São Francisco de Assis foi herege, mas o movimento franciscano foi recuperado por uma rápida e hábil manobra por parte do papa Inocêncio III, ainda durante a vida do próprio Francisco. Podemos dizer que as três maiores expressões da heresia medieval são Joaquim de Fiore, Francisco de Assis e Mestre Eckhart [...].

A novidade do movimento iniciado por Martim Lutero consiste no fato de não ter sido abafado nem recuperado pela hierarquia católica. Após Lutero, a heresia como fenômeno social deixa de existir, dando lugar à formação de outra "igreja" [...] A partir do protestantismo não existem mais heresias, mas sim igrejas diferentes ${ }^{57}$.

A pontuação e a conclusão às quais Hoornaert chega são claras e precisas. Lutero é tributário e herdeiro de inúmeros movimentos de busca de revitalização es-

${ }^{55}$ D. Martin Luthers Werke. Kritische Gesamtausgabe (1883, xxvi, 530-533) apud FERNANDEZ-ARMESTO; WILSON, 1997, p. 16-17.

${ }^{56}$ DREHER, Martin N. Entre a Idade Média e a Idade Moderna: a localização de Lutero e de sua Reforma. In: DREHER, Martin N. (Org.). Reflexões em torno de Lutero. São Leopoldo: Sinodal, 1984. v. II, p. 30-31.

${ }^{57}$ HOONAERT, Eduardo. Martim Lutero, um teólogo que pensa a partir do povo. In: DREHER (Org.), 1984, v. II, p. 15-16. 
piritual e de reformas. O que distingue Lutero é que ele não buscou apenas reforma na vida pessoal ou nas instituições. Antes, preocupou-se com a reforma da doutrina cristã. Lutero, por razões que não serão aqui explanadas para não se incorrer em fuga do tema, foi bem-sucedido onde outros antes dele não o foram, por terem sido perseguidos com violência.

A lembrança de que houve reformas antes da Reforma, em alguns casos, autênticos "protoprotestantismos", é útil e salutar por quebrar uma visão romântica e idealizada que se tem de Lutero e dos demais reformadores. Ademais, essa visão de longo alcance da história é útil para esforços ecumênicos, no sentido de que a Reforma não trouxe nada de novo. Antes, recuperou o que tinha sido dito e/ou buscado por líderes cristãos, medievais e patrísticos. Em outras palavras: muitas das ênfases da Reforma são do tempo da igreja indivisa, sendo assim patrimônio comum de toda a ecumene, e não patrimônio exclusivo desta ou daquela tradição. Essa lembrança tem em si o potencial de ser incentivador de diálogo ecumênico e da busca de pontos de convergência entre as diferentes tradições e confissões cristãs, especialmente quando o mundo lembra o quinto centenário da Reforma Protestante.

\section{Referências}

AKERS, John. Bogomilos. In: Enciclopédia Histórico-Teológica da Igreja Cristã. São Paulo: Vida Nova, 1988. v. I.

BISHOP, Russell K. Ordem Franciscana. In: ELWELL, Walter A. (Org.). Enciclopédia Histórico-Teológica da Igreja Cristã. São Paulo: Vida Nova, 1990. v. III.

BLOCH, Marc. Os reis taumaturgos. O caráter sobrenatural do poder régio. França e Inglaterra. São Paulo: Companhia das Letras, 1993.

BOLLMANN, Anne. The Influence of Devotio moderna in Northern Germany. In: ANDERSEN, Elizabeth; LÄHNEMANN, Henrike; SIMON, Anne. A Companion to Mysticism and Devotion in Northen Germany in the Late Middle Ages. Leiden: Brill, 2014.

BRAUDEL, Fernand. Escritos sobre a história. São Paulo: Perspectiva, 1978.

CLOUSE, Robert G. Albigenses. In: Enciclopédia Histórico-Teológica da Igreja Cristã. São Paulo: Vida Nova, 1988. v. I.

DAVIDS, Peter H. Devotio Moderna. In: ELWELL, Walter A. (Org.). Enciclopédia Histórico-Teológica da Igreja Cristã. São Paulo: Vida Nova, 1990. v. II.

DOUGLAS, J. D. Groote, Gerard. In: ELWELL, Walter A. (Org.). Enciclopédia Histórico-Teológica da Igreja Cristã. São Paulo: Vida Nova, 1990. v. II.

DOUGLAS, J. D. Irmãos da Vida Comum. In: ELWELL, Walter A. (Org.). Enciclopédia Histórico-Teológica da Igreja Cristã. São Paulo: Vida Nova, 1990. v. II.

FERNANDEZ-ARMESTO, Felipe; WILSON, Derek. Reforma. O Cristianismo e o mundo. 1500-2000. Rio de Janeiro: Record, 1997.

GANDILLAC, Maurice. Gêneses da modernidade. Rio de Janeiro: Editora 34, 1995.

GEORGE, Timothy. Teologia dos Reformadores. São Paulo: Vida Nova, 1994.

GONZALEZ, Justo. A era dos sonhos frustrados. 2. ed. São Paulo: Vida Nova, 1986. (Uma história ilustrada do cristianismo, v. 5).

GONZALEZ, Justo. A era dos reformadores. São Paulo: Vida Nova, 1983. (Uma história ilustrada do cristianismo, v. 6).

HOONAERT, Eduardo. Martim Lutero, um teólogo que pensa a partir do povo. In: DREHER, Martin N. (Org.). Reflexões em torno de Lutero. São Leopoldo: Sinodal, 1984. v. II. 
HUIZINGA, Johan. O declínio da Idade Média. 2. ed. Lisboa: Ulisseia, 1996.

KUBRICHT, Paul. Hus, João. In: ELWELL, Walter A. (Org.). Enciclopédia Histórico-Teológica da Igreja Cristã. São Paulo: Vida Nova, 1990. v. II.

LE GOFF, Jacques. São Francisco de Assis. São Paulo: Record, 2001.

LUTERO, Martinho. Da liberdade do cristã. Edição bilíngüe. 2. ed. São Paulo: Editora da UNESP, 1997.

McGRATH, Alister. Origens intelectuais da Reforma. São Paulo: Cultura Cristã, 2007.

OLIVER JR., Guy. Cátaros. In: Enciclopédia Histórico-Teológica da Igreja Cristã. São Paulo: Vida Nova, 1988. v. I.

SCHÜLLER, Osvaldo. John Wiclife a dissolução do universalismo medieval. Canoas: ULBRA, 2002.

SKIDMORE, Thomas. Levi-Strauss, Braudel and Brazil: A Case of Mutual Influence. Bulletin of Latin American Research, v. 22, n. 3, p. 340-349, 2003.

SPOTO, Donald. Francisco de Assis: o santo relutante. Rio de Janeiro: Objetiva, 2003.

VAZ, Henrique C. de Lima. Raizes da modernidade. 2. ed. São Paulo: Loyola, 2012. (Escritos de filosofia VII). 